OPEN ACCESS

Edited by:

Veronica Vella,

University of Catania, Italy

Reviewed by:

Hans Ghayee,

University of Florida, United States Antonio Matrone,

University of Pisa, Italy

*Correspondence:

Wenwei Hu

szdxfsdsyy@163.com

${ }^{\dagger}$ These authors have contributed equally to this work and share first authorship

Specialty section:

This article was submitted to

Cancer Endocrinology,

a section of the journal

Frontiers in Endocrinology

Received: 24 May 2021

Accepted: 22 July 2021

Published: 09 August 2021

Citation:

Shi H, Wang C, Qiang W,

Sun B, Wang $H$, Yuan Y and Hu W (2021) Case Report:

Successful Control of Pulmonary

Metastatic Pheochromocytoma With

lodine-125 Seed Implantation.

Front. Endocrinol. 12:714006. doi: 10.3389/fendo.2021.714006

\section{Case Report: Successful Control of Pulmonary Metastatic Pheochromocytoma With lodine-125 Seed Implantation}

\author{
Hongbing Shi ${ }^{\dagger}$, Chao Wang ${ }^{\dagger}$, Weiguang Qiang, Bai Sun, Hao Wang, Ye Yuan \\ and Wenwei $\mathrm{Hu}^{*}$
}

Department of Oncology, The Third Affiliated Hospital of Soochow University, Changzhou, China

Pheochromocytoma with lung metastases is rare in clinics, and the prognosis of metastatic pheochromocytoma is generally poor. In this case, a 57-year-old woman who presented with hypertension and palpitations was diagnosed with left adrenal pheochromocytoma with lung metastasis in 2010. The patient received left adrenalectomy for pheochromocytoma 10 years ago, but pulmonary lesions had significant progression 7 years ago. The patient was treated with iodine-125 $\left({ }^{125}\right)$ seed implantation for pulmonary lesions. All of the 5 pulmonary lesions achieved partial response 6 months later, further shrank 1 year later, and were successfully controlled for 7 years. This case indicated that ${ }^{125} \mathrm{I}$ seed implantation could be an alternative local therapy for metastatic pheochromocytoma in the lung.

Keywords: pheochromocytoma, metastasis, ${ }^{125}$ | seed implantation, brachytherapy, interventional therapy

\section{INTRODUCTION}

Pheochromocytoma is a rare endocrine neoplasm that arises from chromaffin cells of the adrenal medulla. Approximately $10 \%$ of pheochromocytomas are metastatic pheochromocytomas, and only metastases are the proof for malignant pheochromocytomas (1). Metastases are commonly located in the liver, bones, lymph nodes, and lungs $(2,3)$. For patients with symptomatic metastases or significant disease progression, several local or systemic therapies are available to reduce tumor burden, but standard curative management has not been established so far. Cytoreductive resection, thermal ablation, and external beam radiation therapy (EBRT) are recommended for local management of metastatic pheochromocytomas. Comparing with those therapies, the use of radiopharmaceutical agents or chemotherapy is more suitable for widespread and rapidly progressive metastatic pheochromocytomas $(4,5)$.

Iodine-125 $\left({ }^{125} \mathrm{I}\right)$ seed brachytherapy is a modality of continuous low-dose-rate irradiation, in which a dose of $<1$ Gy per hour is continuously delivered by radioactive sources. ${ }^{125} \mathrm{I}$ seed implantation is the most common approach of ${ }^{125} \mathrm{I}$ seed brachytherapy and it has been performed in various types of locally recurrent or metastatic carcinomas in recent years (6-8). The efficacy of ${ }^{125} \mathrm{I}$ seed implantation in pheochromocytomas has not yet been reported. Herein, we report a case of a patient with metastatic pheochromocytoma in bilateral lungs, who was treated with ${ }^{125}$ I seed implantation 7 years ago and achieved good efficacy. 


\section{CASE REPORT}

In September 2010, a 57-year old woman with hypertension and palpitations was found with a mass in her left adrenal medulla by ultrasound on the regular checkup. She was referred to our hospital 1 month later. Computed tomography (CT) scans displayed a heterogeneous solid tumor, $6.9 \times 5.5 \mathrm{~cm}$ in size, in the left adrenal medulla, as well as two nodules at less than $1 \mathrm{~cm}$ in the right lung (one in the middle lobe, the other in the lower lobe). Three weeks before the surgery, the alpha-adrenergic receptor blocker, phenoxybenzamine (10 mg bid), was used for normalizing blood pressure and heart rate. The patient underwent left adrenalectomy to remove the tumor. The histopathological examination showed that the tumor was pheochromocytoma, and the Pheochromocytoma of the Adrenal Gland Scaled Score (9) is 14. After the surgery, hypertension and palpitations were relieved. CT scans were performed annually, and the lung metastases grew gradually without any symptoms. Three years later (October 2013), contrast-enhanced CT showed increased and enlarged nodules in both lungs. There were five enhanced nodules, including a $2.5 \times 2.3-\mathrm{cm}$ lesion in the right lower lobe, a $2.2 \times 1.8-\mathrm{cm}$ lesion in the right middle lobe, and three $1.0 \times 1.0-\mathrm{cm}$ lesions in the left lobes (Figure 1A). Hypertension reappeared with the blood pressure ranged from 160/100 $\mathrm{mmHg}$ to $180 / 110 \mathrm{mmHg}$, but palpitations were not found. Biochemical testing showed elevated levels of plasma-free normetanephrine (4937 pg/mL, normal range $<160 \mathrm{pg} / \mathrm{mL}$ ) and 24hour urine metanephrine $(633 \mu \mathrm{g}$, normal range $<580 \mu \mathrm{g})$. Additionally, CT-guided percutaneous biopsy of the pulmonary nodule was performed. Histopathological examination confirmed the diagnosis of metastatic pheochromocytoma (Figure 2). For multilocal lesions in bilateral lungs, surgical resection was not suitable, and local minimally invasive therapy might take more benefits than systemic therapy. Considering the fewer side effects and cost, the patient chose the ${ }^{125}$ I seed implantation.

The patient received phenoxybenzamine (10 $\mathrm{mg}$ bid) to control blood pressure 2 weeks before the procedure and 2 months after the procedure. Percutaneous ${ }^{125} \mathrm{I}$ seed implantation was performed under the CT guidance, and local anesthesia was used during the procedure. The implantation plan was determined according to the treatment planning system based on the patient's enhanced CT data. The activity of each implanted ${ }^{125} \mathrm{I}$ seed was $0.7 \mathrm{mCi}$, and the prescription dose of each lesion was 120-140 Gy (10). A total of 80 seeds (32 in the lesion of the right lower lobe, 18 in the lesion of the
A

व

B
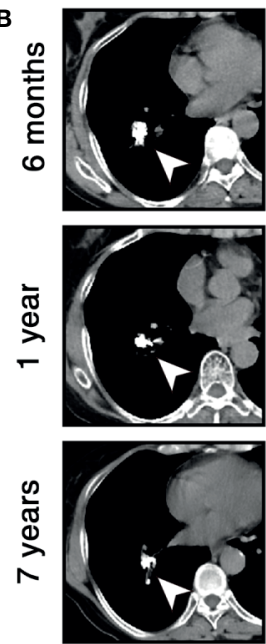
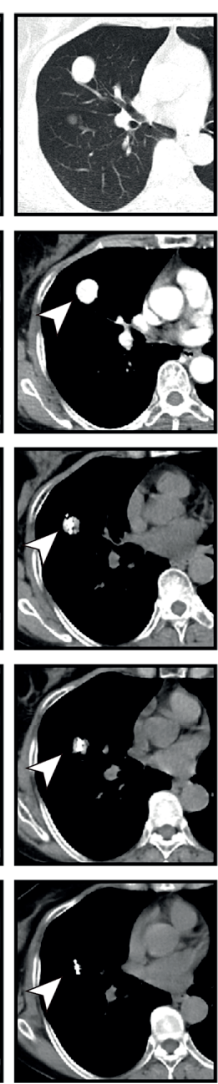
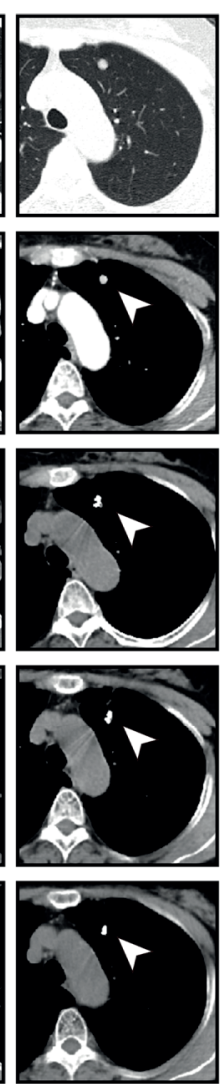
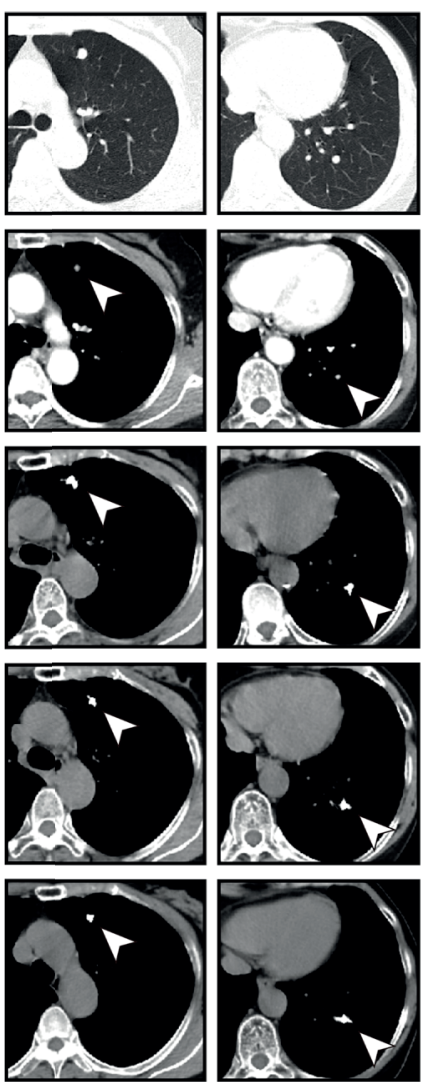

FIGURE 1 | Chest computed tomography (CT) scans of the patient during the follow-up. (A) Before the ${ }^{125}$ seed implantation, contrast-enhanced CT images in lung windows (upper) and mediastinal windows (lower) show 5 enhanced nodules (white arrowheads) in both lungs. (B) Six months, 1 year, and 7 years after ${ }^{125}$ I seed implantation, unenhanced CT images in mediastinal windows show that volume of lesions was significantly reduced within 1 year and remained stable for 7 years. High-density ${ }^{125}$ I seeds were located in the original sites of the lesions. 

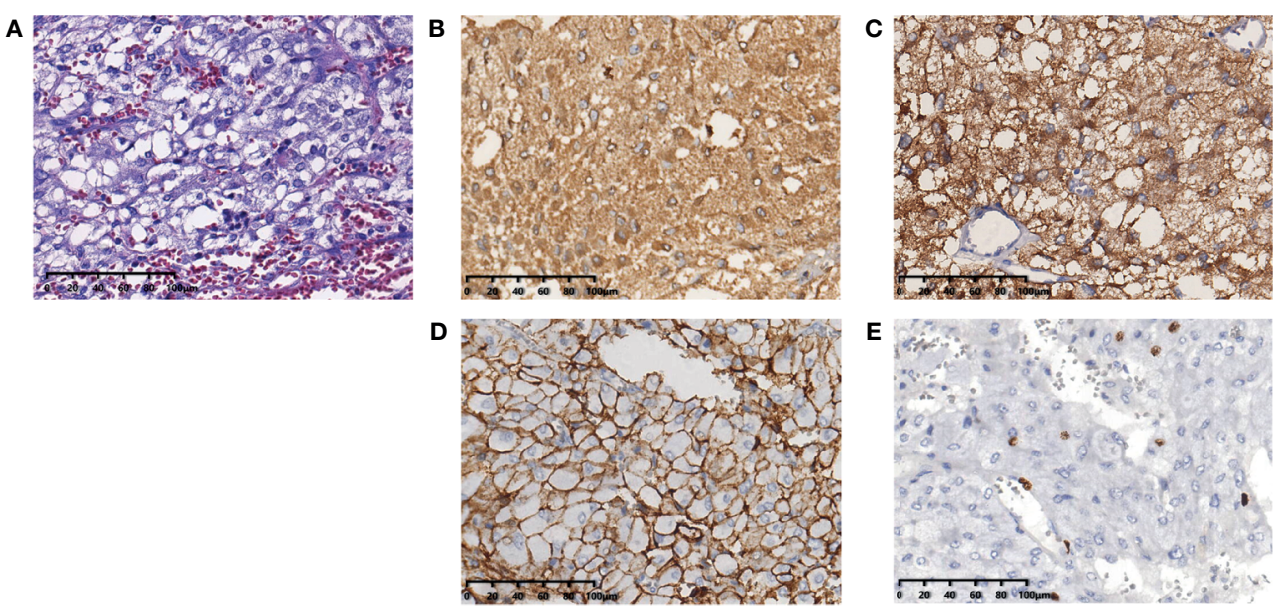

FIGURE 2 | Histopathological examination shows the pulmonary nodules were metastatic pheochromocytoma. (A) Hematoxylin and eosin staining of biopsy specimens shows nests of tumor cells separated by vascular septa (Zellballen). (B) Chromogranin and (C) synaptophysin immunostaining is diffuse strong positive in the tumor cells. (D) CD56 immunostaining is positive in the membrane of the tumor cells. (E) Ki-67 immunostaining shows approximately $5 \%$ of cells are positive. Original magnification $\times 200$.

right middle lobe, 10 in each lesion of the left lobe) were implanted into the target lesions through $18 \mathrm{G}$ puncture needles. No pulmonary hemorrhage, pneumothorax, or chest pain was found during the perioperative period. The patient's secondary hypertension was relieved with the blood pressure of $\leq 140 / 90$ mmHg 2 months later. Levels of 24-hour urine metanephrine and plasma-free normetanephrine returned to normal 2 months and 6 months later, respectively (Table 1). CT scans were performed per 6 months for the first year. The lesions achieved partial response according to Response Evaluation Criteria in Solid Tumors version 1.1 (RECIST v1.1) 6 months later, and further shrank 1 year later (Figure 1B). Thereafter, the patient was followed up with CT scans annually and her disease remained stable for 7 years as of the last follow-up on October 25, 2020.

\section{DISCUSSION}

Pheochromocytoma is a rare tumor in clinics, the incidence of pheochromocytoma is about 2 to 5 cases per million person-years (11). Nearly one-fifth of patients with pheochromocytoma experience disease progression at a slow rate. Compared with most malignant tumors, pheochromocytoma has a relatively better prognosis, but metastatic pheochromocytoma usually has a poor prognosis. A systematic review (12) showed that overall and 5-year mortality rates for metastatic pheochromocytoma were $53 \%$ and $42 \%$, respectively. Pheochromocytoma can release catecholamines and their metabolites, which lead to adrenergic symptoms, such as hypertension, headache, and palpitations. If the tumor is not removed, life-threatening hypertension and cardiac disorders may happen (1). In addition, metastases could also result in lesionrelated mass effect, commonly leading to pain and compression of surrounding structures. For the symptomatic or rapidly progressive metastatic pheochromocytoma, treatment is necessary, and several local or systemic therapies have been successfully used (5).

Surgical resection is the preferred treatment for patients with resectable metastatic pheochromocytomas, and a minimally invasive approach is recommended (13). However, in some cases, such as those with multiple local lesions, patients are not suitable for surgery. Percutaneous interventional techniques, including radiofrequency ablation (RFA), cryoablation, percutaneous ethanol injection (PEI), and cementoplasty, were also reported to be efficient for local control and symptom relief in metastatic pheochromocytomas. A recent study (14) reported the efficacy of ablative therapy for metastatic pheochromocytoma and paraganglioma (PPGL). Thirty-one patients with 123 lesions underwent a total of 69 ablation sessions (42 RFA, 23 cryoablation, and $4 \mathrm{PEI}$ ). Radiographic local control was achieved in $86 \%$ of the ablated lesions ( $86 \%$ with RFA, $86 \%$ with cryoablation, and $50 \%$ with PEI), and improvement in adrenergic symptoms or metastasis-related pain was achieved in $92 \%$ of procedures. Liu et al. (15) reported a case on malignant pheochromocytoma with sacrum metastases, which were treated with cementoplasty after embolization of the internal iliac artery. Although cement-related

TABLE 1 | Biochemical laboratory findings before and after ${ }^{125}$ | seed implantation.

\begin{tabular}{lccccc}
\hline Indicators & Pre & 2 months & 6 months & 1 year & Normal range \\
\hline Plasma-free normetanephrine, $\mathrm{pg} / \mathrm{mL}$ & 4937 & 1081 & 146 & 52 & $<160$ \\
Urine metanephrine, $\mu \mathrm{g} / 24 \mathrm{~h}$ & 633 & 316 & 121 & 90 & $<580$
\end{tabular}


spinal canal stenosis occurred, the patient's neurological deficits improved after circumferential spinal cord decompression.

As another percutaneous interventional technique, ${ }^{125} \mathrm{I}$ seed implantation was first used for the treatment of prostate cancer in the 1970s, and it has been the first-line treatment for localized prostate cancer (16). In recent years, image-guided ${ }^{125} \mathrm{I}$ seed implantation has also been used for the treatment of various primary or metastatic solid tumors, such as lung cancer, liver cancer, bone cancer, and lymph node metastases (10,17-19). Since the common metastatic sites of pheochromocytoma are also the common implanted sites of ${ }^{125} \mathrm{I}$ seeds, we assumed that ${ }^{125}$ I seed implantation could become a feasible treatment in metastatic pheochromocytoma. Our case illustrated that percutaneous ${ }^{125}$ I seed implantation can be safely used to treat metastatic pheochromocytoma in the lung. Thermal ablation techniques such as RFA have the defect of invisible spherical ablation margin during the procedure, due to which adjacent crucial organs may be damaged or tumor may be undertreated (20). The implanted ${ }^{125} \mathrm{I}$ seeds are arranged according to the shape of the tumor. Thus, we believe ${ }^{125}$ I seed implantation could be an alternative treatment for thermal ablation and is more suitable for patients with lesions adjacent to crucial organs.

Pheochromocytoma is sensitive to radiation therapy. The targeted radiolabeled carrier, high-specific-activity (HAS) ${ }^{131} \mathrm{I}-$ metaiodobenzylguanidine ( $\left.{ }^{131} \mathrm{I}-\mathrm{MIBG}\right)$ or ${ }^{177}$ Lutetium-DOTATyr3-Octreotate $\left({ }^{177} \mathrm{Lu}\right.$-DOTATATE), was recommended for the treatment of unresectable metastatic pheochromocytoma if tumors are positive on MIBG scan or somatostatin receptor imaging. As reported in a phase 2 multicenter trial (21) investigating HAS ${ }^{131} \mathrm{I}$ MIBG to treat patients with metastatic or unresectable PPGL, partial response and stable disease were achieved in $23 \%$ and $68 \%$ of patients respectively, and the median overall survival was as long as 36.7 months. However, hematologic toxicity (90\%) and gastrointestinal adverse events, such as nausea (78\%) and vomiting (53\%), were common. A study of 30 patients with metastatic or unresectable PPGL treated with ${ }^{177} \mathrm{Lu}$-DOTATATE displayed similar results (22). Partial response and stable disease were achieved in $23 \%$ and $67 \%$ of patients respectively, and grade 3 or 4 hematologic toxicity was observed in $20 \%$ of patients. EBRT was another recommended palliative therapy for metastatic pheochromocytoma. As literature $(23,24)$ showed, the radiographic local control rate was $81 \%-87 \%$ and the symptom improvement rate was $81 \%-94 \%$ in patients with metastatic PPGL treated with EBRT.

${ }^{125}$ I seed implantation is a modality of internal radiation therapy, which releases continuous low-dose-rate $\mathrm{x}$-ray and $\gamma$ ray. Although the type of radioactive rays and the form of irradiation are different from the radiopharmaceutical agents and EBRT, the pulmonary metastatic pheochromocytoma in our case showed good sensitivity to ${ }^{125} \mathrm{I}$ seed radiation. Compared

\section{REFERENCES}

1. Neumann HPH, Young WFJr., Eng C. Pheochromocytoma and Paraganglioma. N Engl J Med (2019) 381(6):552-65. doi: 10.1056/NEJMra 1806651

2. Plouin PF, Amar L, Dekkers OM, Fassnacht M, Gimenez-Roqueplo AP, Lenders JW, et al. European Society of Endocrinology Clinical Practice with targeted radiopharmaceutical agents and EBRT, ${ }^{125} \mathrm{I}$ seed implantation provides the advantage of delivering higher doses of radiation to the tumor with relative sparing of surrounding normal tissues. The cumulative dose achieved 120-140 Gy in each pulmonary lesion in this case, while the median cumulative dose was only $24 \mathrm{~Gy}$ in EBRT (23). The high cumulative doses delivered by ${ }^{125}$ I seeds could be the main reason for such good efficacy: all 5 pulmonary lesions shrank significantly, the patient's hypertension was relieved, and no new metastasis was found. Moreover, in this case, no radiation-related adverse event was found during follow-up. Damage or stress to the tumor could cause the release of large amounts of catecholamines, aggravating adrenergic symptoms, even resulting in life-threatening hypertension (13). The half-life period of ${ }^{125} \mathrm{I}$ seed is 60.2 days, approximately half of the dose is delivered within 2 months. In our opinion, to reduce catecholamine-related risks, it is reasonable to preventively use the alpha-adrenergic receptor blocker for at least 2 months after implantation.

In conclusion, our case illustrated that ${ }^{125} \mathrm{I}$ seed implantation had a powerful anti-tumor effect on metastatic pheochromocytoma with pulmonary metastases. We propose that ${ }^{125}$ I seed implantation should be further evaluated as an alternative local therapy in patients with unresectable metastatic pheochromocytoma.

\section{DATA AVAILABILITY STATEMENT}

The original contributions presented in the study are included in the article/supplementary material. Further inquiries can be directed to the corresponding author.

\section{ETHICS STATEMENT}

Written informed consent was obtained from the individual(s) for the publication of any potentially identifiable images or data included in this article.

\section{AUTHOR CONTRIBUTIONS}

WH conceived the idea of this case report and was responsible for the treatment. HS, WQ, and YY participated in the treatment. $\mathrm{CW}, \mathrm{BS}$, and HW participated in the follow-up and data collection. HS and CW wrote the first draft of the manuscript. All authors contributed to the article and approved the submitted version.

3. Hamidi O, Young WFJr., Iniguez-Ariza NM, Kittah NE, Gruber L, Bancos C, et al. Malignant Pheochromocytoma and Paraganglioma: 272 Patients Over 55 Years. J Clin Endocrinol Metab (2017) 102(9):3296-305. doi: 10.1210/ jc.2017-00992 
4. De Filpo G, Maggi M, Mannelli M, Canu L. Management and Outcome of Metastatic Pheochromocytomas/Paragangliomas: An Overview. J Endocrinol Invest (2021) 44(1):15-25. doi: 10.1007/s40618-020-01344-z

5. Hamidi O. Metastatic Pheochromocytoma and Paraganglioma: Recent Advances in Prognosis and Management. Curr Opin Endocrinol Diabetes Obes (2019) 26(3):146-54. doi: 10.1097/MED.0000000000000476

6. Zhu HD, Guo JH, Huang M, Ji JS, Xu H, Lu J, et al. Irradiation Stents vs. Conventional Metal Stents for Unresectable Malignant Biliary Obstruction: A Multicenter Trial. J Hepatol (2018) 68(5):970-7. doi: 10.1016/j.jhep.2017.12.028

7. Wang H, Lu J, Zheng XT, Zha JH, Jing WD, Wang Y, et al. Oligorecurrence Non-Small Cell Lung Cancer After Failure of First-Line Chemotherapy: Computed Tomography-Guided (125)I Seed Implantation vs. Second-Line Chemotherapy. Front Oncol (2020) 10:470. doi: 10.3389/fonc.2020.00470

8. Wang H, Wang L, Jiang Y, Ji Z, Guo F, Jiang P, et al. Long-Term Outcomes and Prognostic Analysis of Computed Tomography-Guided Radioactive (125)I Seed Implantation for Locally Recurrent Rectal Cancer After External Beam Radiotherapy or Surgery. Front Oncol (2020) 10:540096. doi: $10.3389 /$ fonc. 2020.540096

9. Thompson LD. Pheochromocytoma of the Adrenal Gland Scaled Score (PASS) to Separate Benign From Malignant Neoplasms: A Clinicopathologic and Immunophenotypic Study of 100 Cases. Am J Surg Pathol (2002) 26(5):551-66. doi: 10.1097/00000478-200205000-00002

10. Zhang F, Wang J, Guo J, Li Y, Huang X, Guan Z, et al. Chinese Expert Consensus Workshop Report: Guideline for Permanent Iodine-125 Seed Implantation of Primary and Metastatic Lung Tumors. Thorac Cancer (2019) 10(2):388-94. doi: 10.1111/1759-7714.12912

11. Berends AMA, Buitenwerf E, de Krijger RR, Veeger N, van der HorstSchrivers ANA, Links TP, et al. Incidence of Pheochromocytoma and Sympathetic Paraganglioma in the Netherlands: A Nationwide Study and Systematic Review. Eur J Intern Med (2018) 51:68-73. doi: 10.1016/ j.ejim.2018.01.015

12. Hamidi O, Young WF Jr, Gruber L, Smestad J, Yan Q, Ponce OJ, et al. Outcomes of Patients With Metastatic Phaeochromocytoma and Paraganglioma: A Systematic Review and Meta-Analysis. Clin Endocrinol (Oxf) (2017) 87(5):440-50. doi: 10.1111/cen.13434

13. Lenders JW, Duh QY, Eisenhofer G, Gimenez-Roqueplo AP, Grebe SK, Murad MH, et al. Pheochromocytoma and Paraganglioma: An Endocrine Society Clinical Practice Guideline. J Clin Endocrinol Metab (2014) 99 (6):1915-42. doi: 10.1210/jc.2014-1498

14. Kohlenberg J, Welch B, Hamidi O, Callstrom M, Morris J, Sprung J, et al. Efficacy and Safety of Ablative Therapy in the Treatment of Patients With Metastatic Pheochromocytoma and Paraganglioma. Cancers (Basel) (2019) 11 (2):195. doi: 10.3390/cancers 11020195

15. Liu S, Zhou X, Song A, Li WA, Rastogi R, Wang Y, et al. Successful Treatment of Malignant Pheochromocytoma With Sacrum Metastases: A Case Report. Medicine (Baltimore) (2018) 97(35):e12184. doi: 10.1097/MD.0000000000012184

16. Zaorsky NG, Davis BJ, Nguyen PL, Showalter TN, Hoskin PJ, Yoshioka Y, et al. The Evolution of Brachytherapy for Prostate Cancer. Nat Rev Urol (2017) 14(7):415-39. doi: 10.1038/nrurol.2017.76
17. Zhang ZH, Zhang W, Gu JY, Liu QX, Ma JQ, Liu LX, et al. Treatment of Hepatocellular Carcinoma With Tumor Thrombus With the Use of Iodine125 Seed Strand Implantation and Transarterial Chemoembolization: A Propensity-Score Analysis. J Vasc Interv Radiol (2018) 29(8):1085-93. doi: 10.1016/j.jvir.2018.02.013

18. Yang Z, Chen G, Cui Y, Su T, Yu J, Xiao G, et al. Iodine-125 Seed Implantation Combined With Arterial Chemoembolization Therapy for Pain Palliation in Metastatic Bone Cancer: A Retrospective Study. Cancer Biol Ther (2019) 20 (2):212-8. doi: 10.1080/15384047.2018.1523847

19. He C, Liu Y, Li Y, Yang L, Li YT, Li SL, et al. Efficacy and Safety of Computed Tomography-Guided (125)I Brachytherapy for Lymph Node Metastatic From Hepatocellular Carcinoma. J Cancer Res Ther (2018) 14(4):754-9. doi: 10.4103/jcrt.JCRT_245_17

20. Jiao D, Wu G, Ren J, Han X. Radiofrequency Ablation Versus 125I-Seed Brachytherapy for Painful Metastases Involving the Bone. Oncotarget (2016) 7 (52):87523-31. doi: 10.18632/oncotarget.11983

21. Pryma DA, Chin BB, Noto RB, Dillon JS, Perkins S, Solnes L, et al. Efficacy and Safety of High-Specific-Activity (131)I-MIBG Therapy in Patients With Advanced Pheochromocytoma or Paraganglioma. J Nucl Med (2019) 60 (5):623-30. doi: 10.2967/jnumed.118.217463

22. Zandee WT, Feelders RA, Smit Duijzentkunst DA, Hofland J, Metselaar RM, Oldenburg RA, et al. Treatment of Inoperable or Metastatic Paragangliomas and Pheochromocytomas With Peptide Receptor Radionuclide Therapy Using 177LuDOTATATE. Eur J Endocrinol (2019) 181(1):45-53. doi: 10.1530/EJE-18-0901

23. Breen W, Bancos I, Young WFJr., Bible KC, Laack NN, Foote RL, et al. External Beam Radiation Therapy for Advanced/Unresectable Malignant Paraganglioma and Pheochromocytoma. Adv Radiat Oncol (2018) 3(1):259. doi: 10.1016/j.adro.2017.11.002

24. Vogel J, Atanacio AS, Prodanov T, Turkbey BI, Adams K, Martucci V, et al. External Beam Radiation Therapy in Treatment of Malignant Pheochromocytoma and Paraganglioma. Front Oncol (2014) 4:166. doi: 10.3389/fonc.2014.00166

Conflict of Interest: The authors declare that the research was conducted in the absence of any commercial or financial relationships that could be construed as a potential conflict of interest.

Publisher's Note: All claims expressed in this article are solely those of the authors and do not necessarily represent those of their affiliated organizations, or those of the publisher, the editors and the reviewers. Any product that may be evaluated in this article, or claim that may be made by its manufacturer, is not guaranteed or endorsed by the publisher.

Copyright (c) 2021 Shi, Wang, Qiang, Sun, Wang, Yuan and Hu. This is an openaccess article distributed under the terms of the Creative Commons Attribution License (CC BY). The use, distribution or reproduction in other forums is permitted, provided the original author(s) and the copyright owner(s) are credited and that the original publication in this journal is cited, in accordance with accepted academic practice. No use, distribution or reproduction is permitted which does not comply with these terms. 